OPEN ACCESS

Edited by:

Alvaro Sanz-Saez,

Auburn University,

United States

Reviewed by:

Joseph Ronald Stinziano,

University of New Mexico,

United States

Amanda Cavanagh,

University of Illinois at

Urbana-Champaign,

United States

*Correspondence:

Carole Coursolle

Carole.Coursolle@Canada.ca

Specialty section: This article was submitted to

Plant Abiotic Stress,

a section of the journal

Frontiers in Plant Science

Received: 18 April 2019 Accepted: 12 September 2019

Published: 25 October 2019

Citation:

Coursolle C, Otis Prud'homme G, Lamothe $M$ and Isabel N (2019)

Measuring Rapid

A-Ci Curves in Boreal Conifers: Black

Spruce and Balsam Fir.

Front. Plant Sci. 10:1276.

doi: 10.3389/fp/s.2019.01276

\section{Measuring Rapid A-Ci Curves in Boreal Conifers: Black Spruce and Balsam Fir}

\author{
Carole Coursolle ${ }^{1 *}$, Guillaume Otis Prud'homme ${ }^{1,2}$, Manuel Lamothe $^{1}$ and Nathalie Isabel ${ }^{1}$ \\ ${ }^{1}$ Laurentian Forestry Centre, Canadian Forest Service, Natural Resources Canada, Québec City, QC, Canada, ${ }^{2}$ Ministère \\ des Forêts, de la Faune et des Parcs, Direction de la recherche forestière, Québec, QC, Canada
}

Climate change is steering tree breeding programs towards the development of families and genotypes that will be adapted and more resilient to changing environments. Making genotype-phenotype-environment connections is central to these predictions and it requires the evaluation of functional traits such as photosynthetic rates that can be linked to environmental variables. However, the ability to rapidly measure photosynthetic parameters has always been limiting. The estimation of $V_{c, \max }$ and $J_{\max }$ using $\mathrm{CO}_{2}$ response curves has traditionally been time consuming, taking anywhere from 30 min to more than an hour, thereby drastically limiting the number of trees that can be assessed per day. Technological advancements have led to the development of a new generation of portable photosynthesis measurement systems offering greater chamber environmental control and automated sampling and, as a result, the proposal of a new, faster, method (RACiR) for measuring $V_{c, \max }$ and $J_{\max }$. This method was developed using poplar trees and involves measuring photosynthetic responses to $\mathrm{CO}_{2}$ over a range of $\mathrm{CO}_{2}$ concentrations changing at a constant rate. The goal of the present study was to adapt the RACiR method for use on conifers whose measurement usually requires much larger leaf chambers. We demonstrate that the RACiR method can be used to estimate $V_{c, \max }$ and $J_{\max }$ in conifers and provide recommendations to enhance the method. The use our method in conifers will substantially reduce measurement time, thus greatly improving genotype evaluation and selection capabilities based on photosynthetic traits. This study led to the developpement of an R package (RapidACi, https://github.com/ManuelLamothe/RapidACi) that facilitates the correction of multiple RACiR files and the post-measurement correction of leaf areas.

Keywords: rapid $A-C_{i}$ curves, boreal conifers, LI-6800, phenotyping, photosynthesis, $V_{\text {cmax }}, J_{\text {max }}$, phenomics

\section{INTRODUCTION}

Climate change is steering tree breeding programs towards the development of families and genotypes that will be adapted and more resilient to the warming climate and thereby ensure the health and productivity of forests (Aitken and Bemmels, 2015). Despite the advances in genomics, the prediction of tree responses to future climate remains challenging because of the difficulty in measuring phenotypes related to adaptation. Making genotype-phenotype-environment connections is central to these predictions but the list of traits reflecting tree adaptation to environment that could be efficiently assessed is limited. Indeed, measuring ecophysiological traits can be laborious and time consuming, thus limiting the ability to establish relationships between 
genotypes and plant response to environmental conditions. Rapid, large-scale screening, or plant phenomics (Furbank and Tester, 2011; Stinziano et al., 2017), are required to overcome these constraints.

Developing indicators for photosynthetic performance are of particular interest when trying to select genotypes that will be adapted to future climates. $V_{c, \max }$, the maximum rate of ribulose-1,5-bisphosphate carboxylation (Rubisco) and $J_{\max }$, the maximum rate of electron transport, are two such parameters (Long and Bernacchi, 2003). These two parameters are also incorporated into Earth System Models (Rogers, 2014) and can be used as "ground truthing" parameters for the development of phenotyping and forest health monitoring platforms using unmanned aerial vehicles (UAVs) and other types of mobile systems in combination with spectral measurements (Dash et al., 2017, Thompson et al., 2018), which is another incentive for the development of a method to obtain reliable estimates rapidly. Estimates of $V_{c, \max }$ and $J_{\max }$ are obtained through the measurement and modelling of photosynthetic response to $\mathrm{CO}_{2}$ concentration ( $A-C_{i}$ curves), which until recently could take anywhere from $30 \mathrm{~min}$ to more than $60 \mathrm{~min}$ per curve (depending on the number of $\mathrm{CO}_{2}$ concentrations measured and the system used), thereby greatly limiting the number of measurements that can be made daily.

Recent technological advances have resulted in the development of a new generation of portable photosynthesis measurement systems. With better chamber environmental controls, automation, logging capabilities and computing power, they now permit much greater sampling densities as well as the possibility of accelerating measurement times. Stinziano et al. (2017) have proposed a new method (RACiR) for measuring $A-C_{i}$ curves. By continuously increasing or decreasing the chamber $\mathrm{CO}_{2}$ concentration (ramping), they were able to take less than $5 \mathrm{~min}$ for each curve. However, this method was developed using poplar leaves (Populus deltoids Barr.) and a small chamber (6 $\mathrm{cm}^{2}$ leaf aperture), which is not really suitable for measuring most conifers where a much larger chamber $\left(36 \mathrm{~cm}^{2}\right.$ leaf aperture in our case) is usually used. The larger leaf chamber volume causes larger differences in response times between the reference and sample chambers due to greater dilution. This, combined with their unique leaf physiology and geometry, requires that the RACiR method be tested on conifers. The objective of the present study was to develop and test the RACiR method on two boreal conifers, balsam fir (Abies balsamea (L.) Mill.) and black spruce (Picea mariana (Mill.) Britton), growing in a common garden experiment set up to test the effects of heating the seedling growth environment, using a larger chamber.

\section{MATERIALS AND METHODS}

\section{Plant Material and Growth Conditions}

The study was conducted using 5-year-old black spruce and balsam fir trees planted in a common garden experiment at the Valcartier experimental station in St-Gabriel-de-Valcartier,
Québec (N 4656'59.93"/W 71²9'53.88"). Bare-root seedlings were planted in triangular plots in May and June 2015. Starting in 2016, half the plots were heated from May to October of each year using $1000 \mathrm{~W}$ infrared lamps between May and October to produce a growing temperature $2{ }^{\circ} \mathrm{C}$ above ambient temperatures. A branch with at least 3 years of growth $(2018,2017,2016)$ was sampled from seven different black spruce (BS) and seven different balsam fir (BF) trees, four growing in heated plots and three growing in unheated control plots. Branches were cut, placed in water, recut and inserted into floral water tubes while still underwater to avoid cavitation. Water levels in the floral tubes were monitored throughout the measuring period and the water was topped up as required using a syringe. All measurements were made on site under normal field conditions.

\section{Gas Exchange Measurements}

An LI-6800 portable photosynthesis system (LI-COR Inc., Lincoln, NE, USA) equipped with the Large Leaf and Needle Chamber $\left(36 \mathrm{~cm}^{2}\right)$ and the large light source was used for all measurements. The dark respiration $(\mathrm{Rd})$ and $\mathrm{CO}_{2}$ response of photosynthesis $\left(A-C_{i}\right)$ of 1-year-old needles were measured on site on July 16, 18 and 19, 2018. Two different methods were used to measure $A-C_{i}$ : (1) The traditional method ( $A-$ $C_{i}$-TRAD), involving net assimilation $\left(\mathrm{A}_{\mathrm{n}}\right)$ measurements at a predetermined set of $\mathrm{CO}_{2}$ concentrations (ex. Long and Bernacchi, 2003) and (2) The rapid method (RACiR), involving continuous measurements over a programmed ramp of changing $\mathrm{CO}_{2}$ concentrations (ex. Stinziano et al., 2017). Both a traditional and a RACiR curve were measured on the same set of needles from each shoot. The RACiR curve was measured first followed by the traditional curve. The same environmental conditions were used for both curve types: 1) $22 \mathrm{mmol} \mathrm{mol}^{-1}$ of $\mathrm{H}_{2} \mathrm{O}$ in the reference cell producing between $\sim 63 \%$ and $79 \%$ relative humidity $(\mathrm{RH})$ in the leaf chamber, depending on the quantity of leaf surface area in the chamber, and producing a variation of $\sim 2 \%$ to $3 \%$ in $\mathrm{RH}$ over the course of measurements for each shoot; 2) $1200 \mu \mathrm{mol} \mathrm{m} \mathrm{m}^{-2} \mathrm{~s}^{-1}$ of light, based on Benomar et al. (2017) and Sendall et al., 2015); 3) chamber air temperature of $25^{\circ} \mathrm{C}$; 4) flow rate of $600 \mu \mathrm{mol} \mathrm{s}{ }^{-1}$; and 5) fan speed of 13,000 rpm.

\section{Rapid $\mathrm{A}-\mathrm{C}_{i}$ Response Curves}

The method used for the RACiR curves was adapted from the one developed by Stinziano et al. (2017) for P. deltoides Barr. leaves using the LI-6800 Portable Photosynthesis System and the Multiflash Fluorometer and Chamber (LI-COR Inc., Lincoln, NE, USA). Shoots were placed in the Large Leaf and Needle Chamber at $420 \mathrm{ppm} \mathrm{CO}_{2}$ concentration $\left(\left[\mathrm{CO}_{2}\right]\right)$ and allowed to acclimate for $\sim 5 \mathrm{~min}$. The LI-6800's Autocontrol function was used to program a "down" ramp from 420 to 20

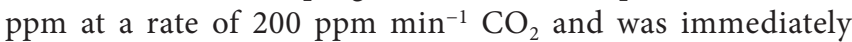
followed, approx. 10 to 15 s later, by an "up" ramp from 20 to

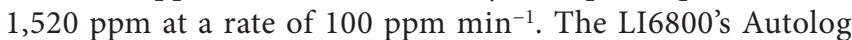
feature was used to record measurements every $2 \mathrm{~s}$. The reference and sample infrared gas analyzers (IRGAs) were matched before the start of each curve. Only the portion of 
A

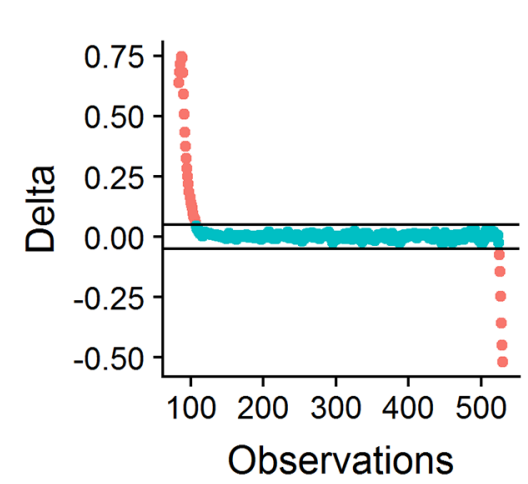

B

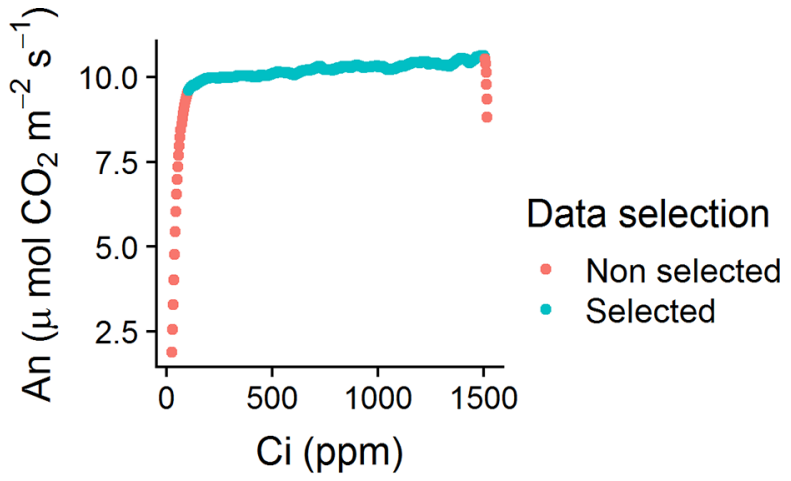

C

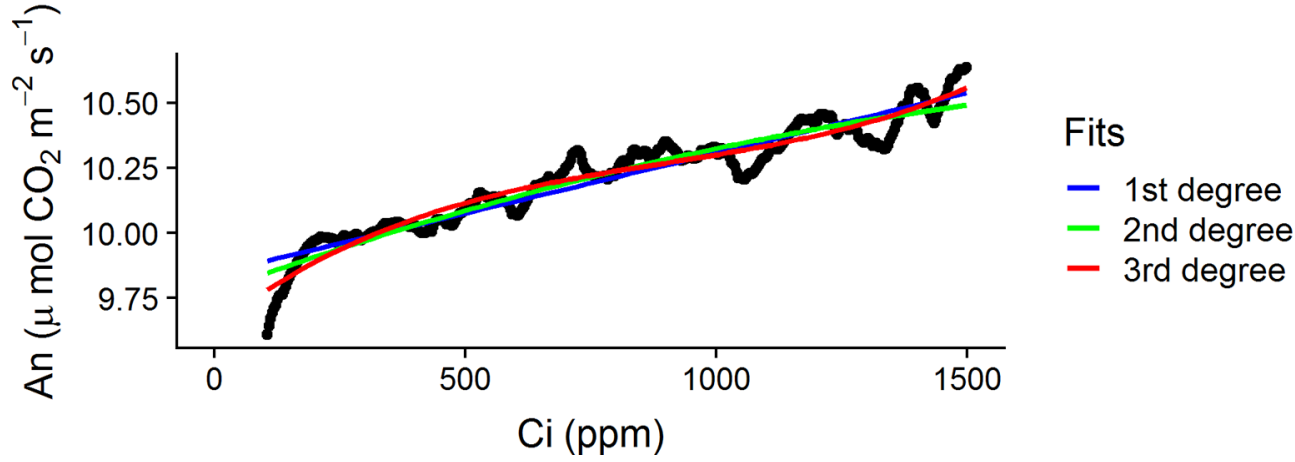

FIGURE 1 | Data selection process for the empty chamber (ECRC) and RACiR response curves. (A) Calculated delta values $\left( \pm 0.05, A n_{i}-A n_{i-1}\right)$ for a selected ECRC, red symbols indicate outliers, blue symbols indicate selected points. (B) $A_{n}$ vs $C_{i}$ for a selected ECRC curve, red symbols indicate non-steady state observations, blue symbols indicate selected points. (C) First, second and third degree polynomials fitted to a selected ECRC for correction of raw RACiR data.

data collected from the "up" ramps (20 to $1,520 \mathrm{ppm}$ ) were used to establish the $\mathrm{CO}_{2}$ response curves. The raw data from these "up ramps" was filtered automatically using a delta threshold value $\left( \pm 0.05, \mathrm{An}_{\mathrm{i}-}-\mathrm{An}_{\mathrm{i}-1}\right)$ to keep only the quasilinear portion of the data, where the chamber mixing is at steady-state, and to also remove outliers (ex: Figures 1A, B).

The raw data obtained from the RACiR curve measurements must be corrected to account for measurement lags between the reference and sample $\left[\mathrm{CO}_{2}\right]$ (Supplementary Figure 1) caused by the mixing volume of the chamber, match offsets and system residual time delays (Stinziano et al., 2017). Data collected from the quasi-linear portion of a RACiR curve measured with the chamber empty (ECRC) was used for this correction. Following Stinziano et al. (2017) and Stinziano et al. (2018), we fitted 1st, 2nd and 3rd degree polynomials (Figure 1C) to this data and the best fitting model according to the Bayesian information criterion (BIC) was used to correct the quasi-linear portion of the RACiR curve measurements. The script used to make the corrections is available on Github (https://github.com/ManuelLamothe/ RapidACi) it can be used to automatically correct multiple files at a time and to carry out post-measurement corrections to leaf area, which are required when measuring non-flat leaves. An example of the analysis can be found in the Supplementary Material (Supplementary Data Sheet 1). ECRCs were carried out at the beginning, middle and end of each day using the same environmental conditions as for the actual measurements.
Three sets of corrected response curve data, one for each empty chamber, were generated for each measured shoot. Each set of response curve data was corrected using empty chamber data obtained the same day.

\section{Traditional $\mathrm{A}-\mathrm{C}_{i}$ Response Curves}

The LI-6800 $\mathrm{CO}_{2}$ response program was used for the $A-C_{i}-$ TRAD curves and the reference $\mathrm{CO}_{2}$ concentrations were set to $420,40,20,40,60,80,100,150,200,300,420,500,700,900$, $1,100,1,300$, and $1,500 \mathrm{ppm}$. Minimum and maximum wait times were set at 60 to $120 \mathrm{~s}$ based on the stability of the $\mathrm{CO}_{2}$ net assimilation rate and the difference between sample and reference $\mathrm{CO}_{2}$ concentrations. The reference and sample infrared gas analyzers (IRGAs) were matched before the measurement at each concentration. The measured shoot was allowed to acclimate at $420 \mathrm{ppm}$ for $\sim 5 \mathrm{~min}$. The $A-C_{i}-\mathrm{TRAD}$ curve was measured on the same needles immediately following the end of the RACiR curve.

\section{Dark Respiration $\left(R_{d \text { Meas }}\right)$ Measurements}

Shoots were removed from the chamber immediately following the $A-C_{i}$-TRAD measurement and dark adapted for at least 30 min by covering the measured shoot with aluminum foil. Shoots were then placed in the darkened LI6800 chamber and allowed to acclimate at $420 \mathrm{ppm}\left[\mathrm{CO}_{2}\right], 25^{\circ} \mathrm{C}$ and $22 \mathrm{mmol} \mathrm{mol}^{-1}$ of $\mathrm{H}_{2} \mathrm{O}$ in the reference before recording $R_{d \_m e a s}$. 


\section{Parameter Estimation and Statistical Analysis}

Timing of Empty Chamber Response Curve (ECRC)

Corrected $\mathrm{CO}_{2}$ response curve data were fitted with the FvCB model using the fitaci function from the Plantecophys $\mathrm{R}$ Package (Duursma, 2015) with the default settings and $R_{d_{-} \text {meas }}$ as an input. $V_{c, \text { max }}, J_{\text {max }}$, and root mean square error (RMSE) were obtained for the three corrected curves (one for each ECRC) from each measured shoot. An analysis of variance on the effect of the timing of the empty chamber measurement series used to correct the RACiR curves was conducted using the nlme R Package (Pinheiro et al., 2018) for mixed models. The analysis was carried out on daily means of $V_{c, \max } J_{\max }$, and RMSE, measurement day was considered a random effect and empty chamber timing (morning, mid-day and afternoon) was considered a fixed effect.

\section{Comparison of Traditional and Rapid $\mathrm{CO}_{2}$ Response Curve Parameters}

$V_{c, \text { max }}$ and $J_{\max }$ were generated for the $A-C_{i}-$ TRAD and RACiR curves by fitting the FvCB model using the Plantecophys R package (Duursma, 2015) with the default settings of the fitaci function and $R_{d \_ \text {meas }}$ as an input. A third set of parameters was generated using the portion of the measured RACiR curve between 200 and 800 ppm of intercellular $\mathrm{CO}_{2}$ concentration $\left(C_{i}\right)$ (RACiR-Partial). An analysis of variance for repeated measures on the effect of the curve type was conducted using the nlme R Package (Pinheiro et al., 2018). Curve type was the repeated factor, tree was considered as a random effect and species, curve type and their interaction were considered fixed effects. The heating effect (main and interactions with curve type) was included as a fixed effect in the original ANOVA model but found to be non-significant $\left(V_{c, \text { max }}: \mathrm{F}=0.6604\right.$, $\mathrm{p}=0.4334$ for the main effect and $\mathrm{F}=2.4311, \mathrm{p}=0.1135$ for the interaction; $J_{\max }: \mathrm{F}=1.2578, \mathrm{p}=0.2883$ for the main effect and $\mathrm{F}=$ $1.7539, \mathrm{p}=.1987$ for the interaction) so it was removed from the final model.

Dark respiration estimates were also obtained using the Plantecophys R package (Duursma, 2015), with its default settings for each curve type, so as to provide additional information on the performance of the three curve fitting methods. An analysis of variance on the effect of the method used to estimate dark respiration, measured $\left(R_{d \_ \text {meas }}\right)$ or estimated using $A-C_{i}-$ $\operatorname{TRAD}\left(R_{d \_a c i}\right)$, RACiR $\left(R_{d \_ \text {racir }}\right)$ and RACiR-Partial $\left(R_{d \_p a r t}\right)$, was conducted using the same parameters as for $V_{c, \max }$ and $J_{\max }$. Again, the heating effect (main and interactions with measurement type) was included as a fixed effect in the original ANOVA model but found to be non-significant $(\mathrm{F}=1.1313, \mathrm{p}=0.3125$ for the main effect and $\mathrm{F}=0.0782, \mathrm{p}=0.9713$ for the interaction) so it was removed from the final model.

\section{RESULTS}

\section{Timing of Empty Chamber Response Curve Measurements (ECRC)}

Three ECRCs were generated per day in an attempt to determine how often an empty chamber response curve needed to be generated to correct the raw RACiR curve measurements. The
TABLE 1 | LSmeans of $V_{c, \max }, J_{\max }$ and RMSE generated using morning, mid-day and late afternoon empty chamber corrections are shown.

\begin{tabular}{|c|c|c|c|c|c|c|}
\hline \multirow[t]{2}{*}{ ECRC } & \multicolumn{2}{|c|}{ 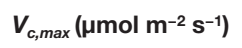 } & \multicolumn{2}{|c|}{$J_{\max }\left(\mu \mathrm{mol} \mathrm{m} \mathrm{m}^{-2} \mathrm{~s}^{-1}\right)$} & \multicolumn{2}{|c|}{ RMSE } \\
\hline & Mean & SE & Mean & SE & Mean & SE \\
\hline Morning & $71.1841^{a}$ & 4.5118 & $127.2851^{a}$ & 5.9813 & $10.4003^{a}$ & 1.4394 \\
\hline Mid-day & $64.1333^{a}$ & 4.5118 & $119.8836^{b}$ & 5.9813 & $9.8551^{a}$ & 1.4394 \\
\hline $\begin{array}{l}\text { Late } \\
\text { Afternoon }\end{array}$ & $70.6677^{a}$ & 4.5118 & $121.2287^{a, b}$ & 5.9813 & $10.7410^{a}$ & 1.4394 \\
\hline
\end{tabular}

Means followed by the same letter are not significantly different $(p<0.05)$ for the variable in question.

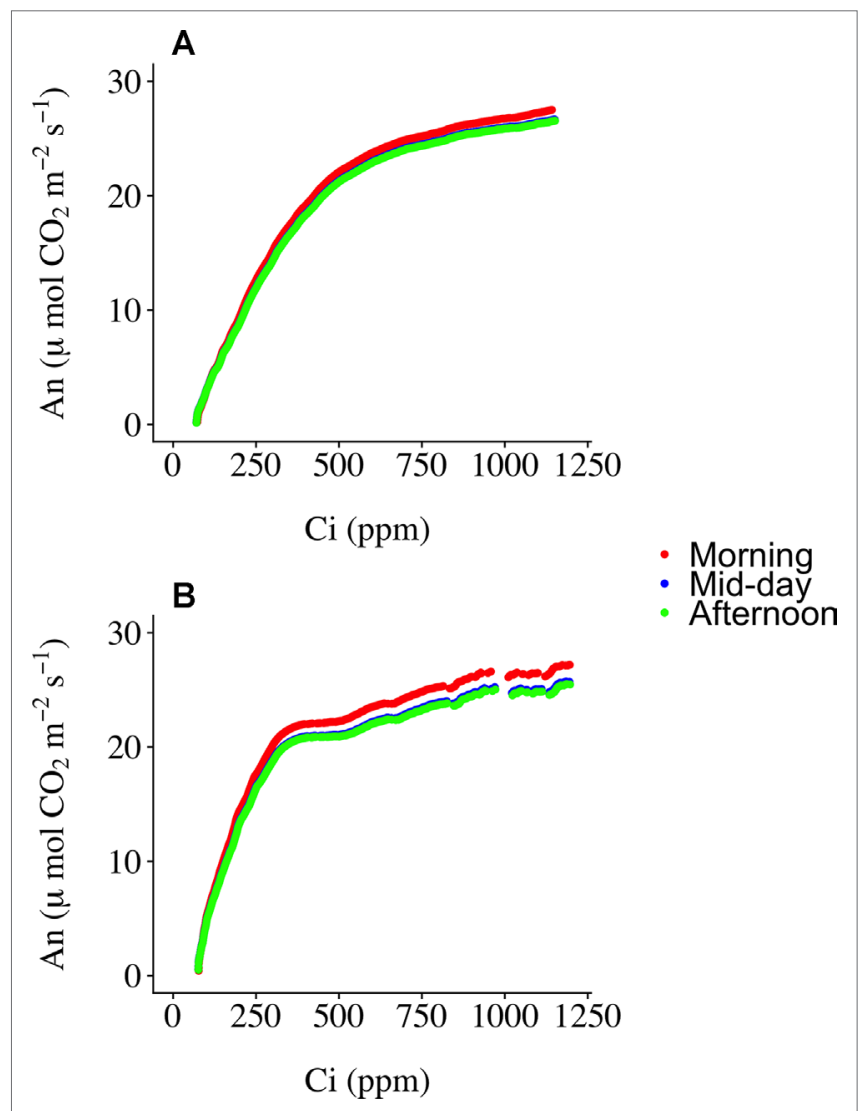

FIGURE 2 | Corrected RACiR curves using the morning, mid-day and afternoon empty chamber response curves (ECRC) for a selected balsam fir (A) and black spruce (B) shoot.

analyses of variance indicated that the timing of the generation of the ECRC had no significant effect on $V_{c, \max }(\mathrm{F}=0.7588, \mathrm{p}=0.5256)$ generated using the $\mathrm{F}_{\mathrm{v}} \mathrm{CB}$ model. However, ECRC timing had a significant effect on $J_{\max }(\mathrm{F}=7.8493, \mathrm{p}=0.0412)$, values generated using the morning ECRC being significantly higher $(\mathrm{p}<0.05)$ than those generated using the mid-day ECRC (Table 1). Finally, RMSE of the fitted $\mathrm{F}_{\mathrm{v}} \mathrm{CB}$ models were not significantly affected by the timing of the ECRC $(F=1.25961, p=0.3765$, Table 1). Figure 2 illustrates the correction effect on the net assimilation rates for a selected balsam fir and black spruce tree. The differences appear to be minimal. The mid-day empty chamber response curve was chosen to correct the RACiR curves for the comparison 


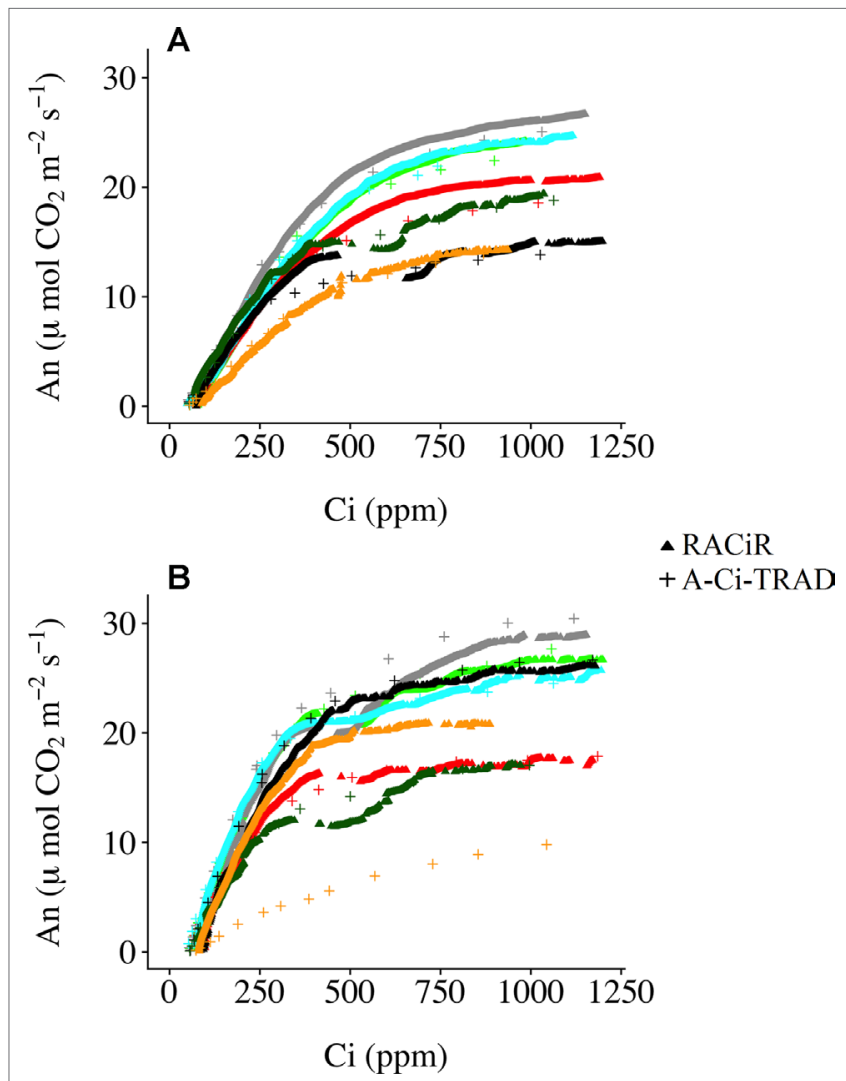

FIGURE 3 | Traditional (A-C $C_{-}$-TRAD) and rapid (RACiR) $\mathrm{CO}_{2}$ response curves for the seven balsam fir (A) and seven black spruce (B) shoots measured.

between traditional and rapid response curves since it was the measurement that was the closest in timing to the largest number of RACiR curves. Furthermore, the $J_{\max }$ generated by the morning empty chamber was the only parameter that was significantly different from the mid-day and afternoon empty chamber curves.

\section{Comparison of Traditional and Rapid $\mathrm{CO}_{2}$ Response Curves and Parameters}

Figure 3 presents $A-C_{i}$-TRAD and corrected RACiR curves for the balsam fir (a) and black spruce (b) shoots measured. Generally, there is good agreement between the two types of curve when $C_{i}$ is below $500 \mathrm{ppm}$ and where $d \mathrm{An} / d C_{i}$ is high. However, there is greater variability and deviation between the two types of curves at higher $C_{i}$ concentrations. Also, small drops in net assimilation within the approximate range of 450-600 ppm $C_{i}$ can be seen for the RACiR curves of some trees. These data points were considered erroneous and removed before fitting the FvCB model. Figure 4 presents the fitted FvCB model using A$C_{i}-\operatorname{TRAD}(\mathrm{a}, \mathrm{d}), \operatorname{RACiR}(\mathrm{b}, \mathrm{e})$ and RACiR-Partial $(\mathrm{c}, \mathrm{f})$ data for a selected balsam fir (a, b, c) and black spruce (d, e, f) shoot. RMSEs of the fitted FvCB models ranged from 2.224 to 13.746 for the $A-C_{i}$-TRAD curves, from 3.834 to 21.787 for the RACiR curves and from 3.243 to 15.065 for the RACiR-Partial curves.
An ANOVA conducted for the response curve parameters $\left(V_{c, \max }, J_{\max }\right)$ and RMSE of the fitted models indicated that the response curve type did not significantly affect either $V_{c, \text { max }}$ or $J_{\text {max }}$, but the RMSE of the models were significantly different (Tables 2, 3). The RMSEs of the fitted RACiR and RACiR-Partial curves were significantly but only slightly to moderately higher than the RMSE of the fitted $A-C_{i}$-TRAD curve.

The statistical analyses indicate that dark respiration was significantly affected $(\mathrm{F}=5.4684, \mathrm{p}=0.0033)$ by the estimation method used. The $A-C_{i}$-TRAD curve yielded the lowest dark respiration $\left(R_{d \_a c i}\right)$ value while $R_{d \_ \text {meas }}$ was the highest. $R_{d \_a c i}$ was the only dark respiration measurement that was significantly different from $R_{d \_ \text {meas }}($ Table 4$) . R_{d_{-} \text {part }}$ was quite similar to $R_{d_{-} a c i}$ while $R_{d_{-} \text {racir }}$ was closer to $R_{d_{-} \text {meas }}$.

\section{DISCUSSION}

\section{LI-6800 Configuration Considerations for Conifer Needle Measurements}

Compared to previously published studies describing the RACiR method applied to flat leaves (Stinziano et al., 2017; Pilon et al., 2018), the needle-leaf geometry of conifer species requires a different instrument configuration for photosynthesis measurements. A much larger leaf chamber $\left(193.7 \mathrm{~cm}^{3}\right.$, large needle and leaf chamber, vs $87.3 \mathrm{~cm}^{3}$ for the fluorometer chamber, in our case) is generally used, thereby leading to a greater "lag time" required for the differences between the sample and reference $\left[\mathrm{CO}_{2}\right]$ to stabilize compared to the smaller chambers. We noted "lag times" of between 48 and $92 \mathrm{~s}$. $($ Mean $=63.4, \mathrm{SE}=4.0)$ compared to the 20-30 s reported by Stinziano et al., 2017 for poplar leaves. The larger lag times caused by the larger cuvette mean that a greater number of potential data points at the start of the ramp (low Ci concentrations in our case) are lost, so preliminary tests should always be carried out to adequately identify the starting $\mathrm{CO}_{2}$ concentration for the ramp. The same should apply for the identification of the ramp end point.

Preliminary tests using a controlled target leaf VPD revealed the existence of periodic noise in the empty chamber measurements caused by adjustments in the $\mathrm{H}_{2} \mathrm{O}$ control loop and the large chamber volume (Pers. Comm: D. Lynch, LI-COR Inc., Lincoln, NE, USA). This led at times to unrealistic, negative $C_{i}$ values and was remedied by controlling the $\mathrm{H}_{2} \mathrm{O}$ content of the air in the reference cell instead. Preliminary tests allowed us to choose a target concentration $\left(22 \mathrm{mmol} \mathrm{mol}^{-1}\right)$ which produced RHs between $\sim 63$ and $79 \%$ in the leaf chamber, thereby assuring that shoot samples were not stressed. This also produced stomatal conductances that were high enough to minimize noise in the $\mathrm{H}_{2} \mathrm{O}$ analyzer, which minimized noise in the calculated $C_{i}$ values (Pers. Comm: D. Lynch, LI-COR Inc., Lincoln, NE, USA).

\section{Timing of Empty Chamber Response Curve Measurements (ECRC)}

Determining the best moment to conduct the ECRC so as to keep the number of required ECRCs to a minimum is an important factor given that one of the main reasons for using the RACiR method is reducing the overall measurement time 

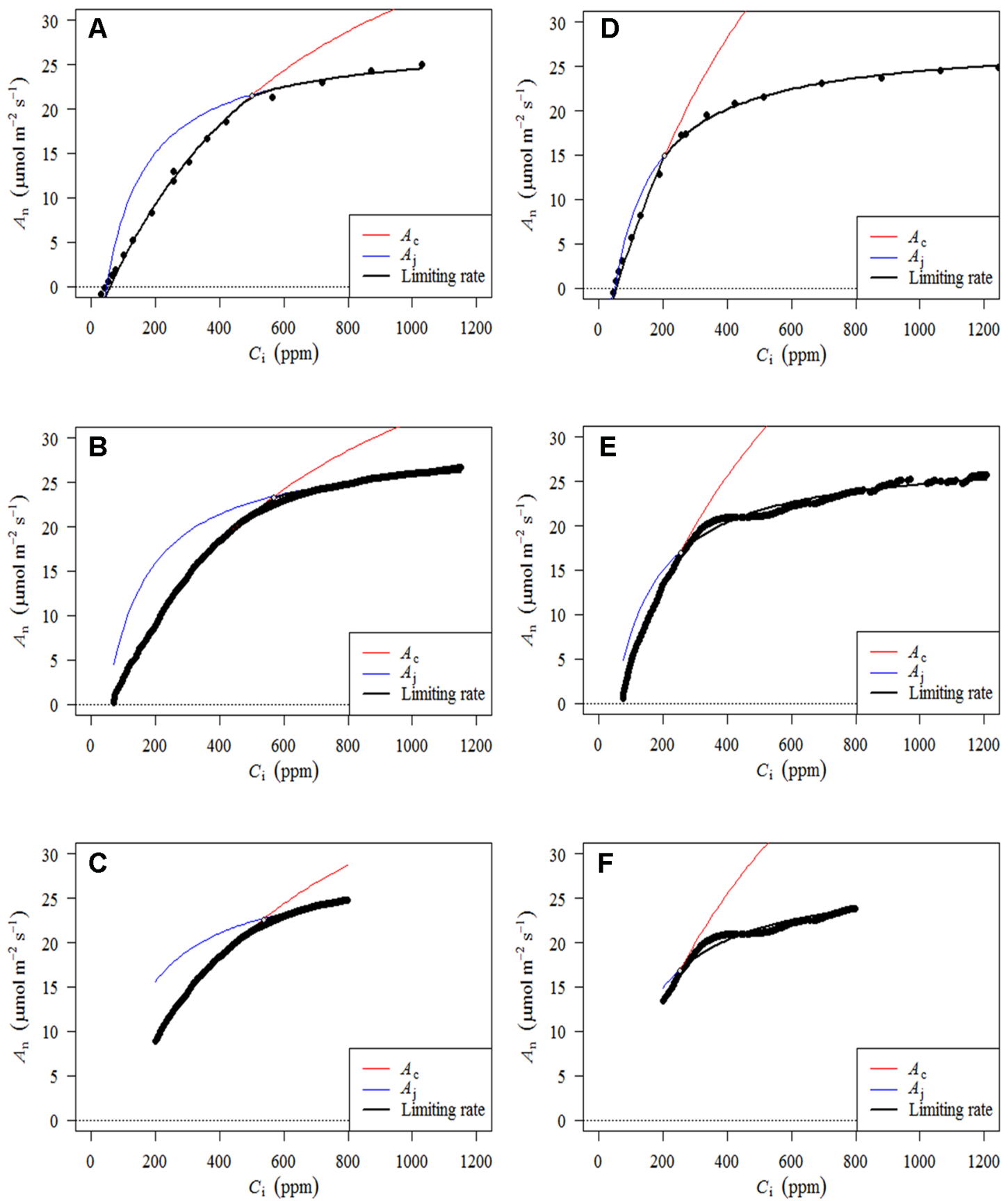

FIGURE 4 | Fitted FvCB models using A-C,-TRAD (A, D), RACiR (B, E) and RACiR-Partial (C, F) data for a selected Balsam fir (A, B, C) and black spruce (D, E, F) shoot. The graphs were generated by the fitaci function of the Plantecophys R package (Duursma, 2015) using the default settings and $R_{d \_ \text {meas }}$ as an input.

TABLE 2 | Results of the ANOVA for the comparison of $V_{c, \max }, J_{\max }$ and RMSE generated by the FVCB model using the three different response curve methods.

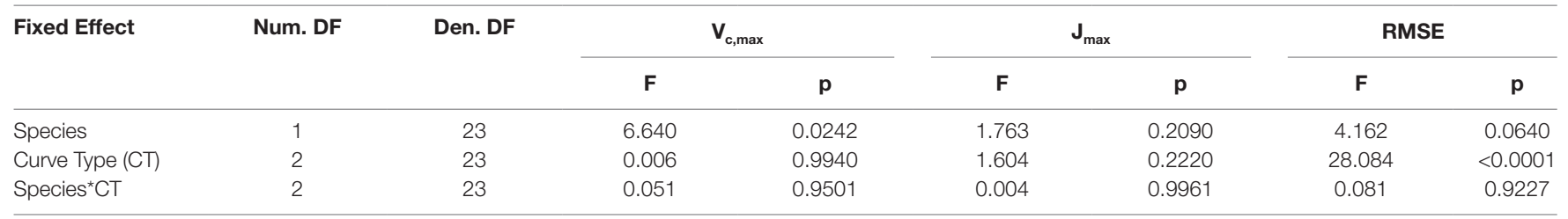

Num. DF, numerator degrees of freedom; Den. DF, denominator degrees of freedom. 
TABLE 3 | LSmeans for $V_{c, m a x}, J_{\max }$ and RMSE generated by the 3 different types of curves.

\begin{tabular}{|c|c|c|c|c|c|c|}
\hline \multirow[t]{2}{*}{ Curve type } & \multicolumn{2}{|c|}{ 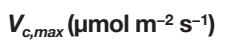 } & \multicolumn{2}{|c|}{$J_{\max }\left(\mu \mathrm{mol} \mathrm{m} \mathrm{m}^{-2} \mathrm{~s}^{-1}\right)$} & \multicolumn{2}{|c|}{ RMSE } \\
\hline & Mean & SE & Mean & SE & Mean & SE \\
\hline$A-C_{i}-\mathrm{TRAD}$ & $62.09^{a}$ & 1.09 & $112.60^{a}$ & 8.34 & $3.73^{a}$ & 1.14 \\
\hline RACiR & $62.02^{a}$ & 1.09 & $119.59^{a}$ & 8.34 & $8.59^{b}$ & 1.14 \\
\hline RACiR_Partial & $61.59^{a}$ & 1.09 & $118.42^{a}$ & 8.34 & $6.10^{c}$ & 1.14 \\
\hline
\end{tabular}

Means followed by the same letter are not significantly different $(p<0.05)$ for the variable in question.

for producing photosynthetic parameters that can be used for phenotyping and health/stress monitoring. Three ECRCs were measured daily, one in the morning before the first shoot measurement, one around mid-day and one in the late afternoon after the last shoot measurement of the day. The $J_{\max }$ generated by the morning ECRC was the only parameter that was significantly different among the ECRCs (Table 1) and the $\mathrm{A}_{\mathrm{n}}$ vs $C_{i}$ relationships obtained from the three different corrected RACiR curves were quite similar (Figure 2). The significantly higher $J_{\max }$ generated by the morning ECRC may have resulted from the fact that we matched the reference and sample IRGAs before measuring each RACiR curve. In a letter published after the conclusion of our study, Stinziano et al., 2018 recommend using the same match for the ECRC and RACiR curves. In fact, we noticed that the largest match adjustments tended to occur towards the beginning of the day and would stabilize thereafter, which most likely explains the lack of significant differences between the RACiR parameters calculated using the mid-day and late afternoon ECRCs. Given our results, we feel that it is most likely feasible to conduct only one ECRC per measurement run per day as long as matches are checked regularly, remain constant and chamber settings do not change. It would also probably be best to run the LI-6800 at the desired chamber settings for several minutes and conduct more than one match before starting a measurement run.

\section{RACiR Vs Traditional $\mathrm{CO}_{2}$ Response Curves}

Figure 3 presents the corrected "raw" response curve data generated by the RACiR and $A-C_{i}$-TRAD methods for the seven balsam fir a) and seven black spruce b) shoots. With the exception of one black spruce shoot, there is generally good agreement when $d \mathrm{An} / d C_{i}$ is high (at $C_{i}$ values below $\sim 500 \mathrm{ppm})$, the area related to Rubisco activity $\left(V_{c, \text { max }}\right)$, but there is more variability at higher $C_{i}$ values related to RuBP regeneration $\left(J_{\max }\right.$; Long and Bernacchi, 2003). These results are generally similar to those reported by Stinziano et al. (2017) and Taylor and Long (2018), using an LI-6800, and to Bunce, 2018, using a CIRAS-3. We believe that the divergence between the two response curve types for one of the black spruce shoots may be linked to a problem with the $A-C_{i}$-TRAD measurement and not the RACiR method, given the unusual form of the $A-C_{i}$-TRAD curve compared to the others. Contrary to Taylor and Long (2018), we did
TABLE 4 | LSmeans for measured dark respiration $\left(R_{d_{-} \text {meas }}\right)$ and dark respiration estimated from the A-C - TRAD $\left(R_{d \_a c i}\right)$, RACiR $\left(R_{d \_ \text {racir }}\right)$ and RACiR-Partial $\left(R_{d \_ \text {part }}\right)$ response curves.

\begin{tabular}{lcc}
\hline & Dark Respiration & \\
\hline Measurement Type & Mean $\left(\boldsymbol{\mu}{\left.\mathbf{m o l ~} \mathbf{~}^{-2} \mathbf{~ s}^{-1}\right)}\right.$ & SE \\
\hline Measured & $2.19^{\mathrm{a}}$ & 0.40 \\
$A-C_{i}-$ TRAD & $0.52^{\mathrm{b}}$ & 0.40 \\
RACiR & $1.85^{\mathrm{a}, \mathrm{b}}$ & 0.40 \\
RACiR-Partial & $0.78^{\mathrm{a}, \mathrm{b}}$ & 0.40 \\
\hline
\end{tabular}

Means followed by the same letter are not significantly different $(p<0.05)$.

not observe significant offsets for $\mathrm{CO}_{2}$ compensation points. $\mathrm{CO}_{2}$ compensation points calculated using RACiR data were generally higher (62.5 without $R_{d_{\_} \text {meas }}$ and 70.6 using $R_{d \_ \text {meas }}$ compared to $A-C_{i}-\mathrm{TRAD}$ (51.1 without $R_{d_{-} \text {meas }}$ and $68.1 \mathrm{using}$ $R_{d \_ \text {meas }}$ ) data but not significantly different ( $\mathrm{p}=0.06$ without $R_{d \_ \text {meas }}$ and 0.39 using $\left.R_{d \_ \text {meas }}\right)$. This would seem to confirm the assertion by Stinziano et al. (2018) that ramp rates above 100 ppm $\min ^{-1}$ can be problematic. Using measured values for dark respiration seems to reduce offsets.

Our results (Table 4) indicate that the dark respiration $\left(R_{d}\right)$ estimated by the FvCB model using the RACiR method

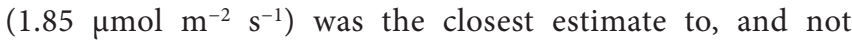

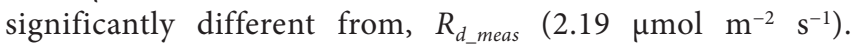
Furthermore, although considerably lower, $R_{d}$ estimated using the RACiR-Partial method $\left(0.78 \mu \mathrm{mol} \mathrm{m} \mathrm{m}^{-2} \mathrm{~s}^{-1}\right)$ was not significantly different from $R_{d \_ \text {meas }}$. The $R_{d}$ estimated using the $A-C_{i}$-TRAD method $\left(0.52 \mu \mathrm{mol} \mathrm{m} \mathrm{m}^{-2} \mathrm{~s}^{-1}\right)$ was considerably lower and significantly different from $R_{d_{-} \text {meas }}$. These results indicate that the RACiR method performs very well when used to estimate dark respiration and this better performance may be linked to the much larger number of data points available for the estimate compared to $A-C_{i}-$ TRAD data.

We found that there were no significant differences among the $V_{c, \max }$ and $J_{\max }$ values generated by the traditional or either of the two rapid response curve methods (Tables 2 and 3 ) when $R_{d \_ \text {meas }}$ was used as an input to the FvCB model. $V_{c, \max }$ values ranged from 61.59 to $62.02 \mu \mathrm{mol} \mathrm{m} \mathrm{m}^{-2} \mathrm{~s}^{-1}(\mathrm{SE}=1.09)$ and $J_{\max }$ values ranged between 112.6 and $119.59 \mu \mathrm{mol} \mathrm{m} \mathrm{m}^{-2} \mathrm{~s}^{-1}$ $(\mathrm{SE}=8.34)$. However, a separate ANOVA looking at $V_{c, \max }$ and $J_{\text {max }}$ generated without using $R_{d_{-} \text {meas }}$ as an input revealed that the curve fitting method had a significant effect on the $J_{\text {max }}$ generated $(\mathrm{F}=5.3946, \mathrm{p}=0.0116)$, the RACiR method $($ Mean $=117.63, \mathrm{SE}=8.7215)$ producing a significantly greater $J_{\max }$ compared to the $A-C_{i}-$ TRAD method (Mean $=103.02$, $\mathrm{SE}=8.72$ ). This result is not surprising given that the $A-C_{i}-$ TRAD method generated dark respiration estimates that were significantly lower than the measured values. Furthermore, an ANOVA conducted to analyze the effect of using $R_{d_{-} \text {meas }}$ vs estimated $R_{d}$ on the generation of $V_{c, \max }$ and $J_{\max }$ values by the $A-C_{i}-$ TRAD method revealed that using $R_{d_{-} \text {meas }}$ had a significant $\left(V_{c, \text { max }}: \mathrm{F}=11.1819, \mathrm{p}=0.0074 ; J_{\text {max }}: \mathrm{F}=54.7402\right.$, $\mathrm{p}<0.0001)$ effect. 
These results clearly show that the RACiR method can be used for a larger chamber size required by conifers and that measuring dark respiration so as to provide the most accurate input to the FvCB model improves the estimated $J_{\max }$. Also, we believe that using the RACiR method when $R_{d \_ \text {meas }}$ is not available would produce the best estimates of $V_{c, \max }$ and $J_{\max }$ given that this method provides an estimate of dark respiration that is much closer to, and not significantly different from, the measured dark respiration when compared to the $A-C_{i}-$ TRAD method.

Results concerning statistical comparisons involving the values generated by the RACiR-Partial method should be interpreted with caution. We did not generate a complete independent set of $\mathrm{CO}_{2}$ response curves for this method but, instead, used a subset of the data that were generated by the RACiR curves. This may have led to some autocorrelation among the data, but we believe that the potential of using smaller $\left[\mathrm{CO}_{2}\right]$ ranges for $\mathrm{CO}_{2}$ response curves of conifers should be further investigated, the smaller the required range, the faster the measurement.

\section{CONCLUSIONS AND RECOMMENDATIONS}

1) The RACiR method can be used for measuring conifers using large needle and leaf chambers, $193.7 \mathrm{~cm}^{3}$ in our case. The exact length of the ramp as well as the appropriate chamber environmental conditions need to be identified during pre-tests and may vary depending on the species and size of chamber used.

2) Typically, a traditional $A-C_{i}$ takes between 30 and $60 \mathrm{~min}$, approx. 30 to $36 \mathrm{~min}$ (excluding acclimation time) in our case, depending on the number of points and wait times at each $\mathrm{CO}_{2}$ concentration. A total maximum time of approximately $22 \mathrm{~min}$ was required to measure a full RACiR curve using the method we have developed. However, as shown by our analysis of the partial RACiR curves (between 200 and 800 ppm internal $\mathrm{CO}_{2}$ concentration), we believe that total measurement time could be reduced by at least $50 \%$ by reducing the ramp range. This method could be used to obtain "ground truthed" photosynthetic capacity estimates to validate air-borne spectral measurements and thereby accelerate and facilitate the development of plant stress and phenotyping platforms.

3) As suggested by Stinziano et al. (2018), we believe that carrying out an empty chamber response curve measurement (ECRC) to correct the RACiR measurements should be carried out for each RACiR measurement series, i.e. at least once a day, and not necessarily after each RACiR measurement, and when environmental conditions in the chamber change. Our findings indicate that the timing is less important as long as

\section{REFERENCES}

Aitken, S. N., and Bemmels, J. B. (2015). Time to get moving: assisted gene flow of forest trees. Evol. Appl. 9, 271-290. doi: 10.1111/eva.12293

Benomar, L., Lamhamedi, M. S., Oeoin' S. Rainville, A., Lambert, M.-C., Margolis, H. A., Bousquet, J., et al. (2017). Thermal acclimation of photosynthesis and respiration of southern and northern white spruce seed sources tested along a the match adjustment remains constant for all of the measured curves in the series.

4) Whenever possible, we recommend measuring dark respiration independently so as to produce the best possible estimates of $V_{c, \max }$ and $J_{\max }$. This could be achieved by using a second photosynthesis measuring system so as to decrease measurement time.

\section{DATA AVAILABILITY STATEMENT}

The datasets generated for this study are available on request to the corresponding author. Also, data from one uncorrected RACiR curve and its corresponding ECRC and ACi-TRAD are provided at https://github.com/GuillaumeOtisPrudhomme/TestFiles for use with the example analyses in Data Sheet 1.

\section{AUTHOR CONTRIBUTIONS}

CC, with input from GP, contrived the study and wrote the manuscript. GP produced the figures. GP and CC collected and analyzed the data. ML provided input to the statistical analysis. ML and GP developed the scripts used to correct the RACiR curves with input from CC. GP and NI read and commented on the manuscript.

\section{FUNDING}

Funding was provided to NI by the Genomics Research and Development Initiative (GRDI) of the government of Canada.

\section{ACKNOWLEDGMENTS}

The authors would like to thank Doug Lynch (LI-COR Inc., Lincoln, NE, USA) for his suggestions concerning RACiR measurement methods and Gilbert Éthier (Faculté des sciences de l'agriculture et de l'alimentation, Université Laval, Québec, QC, Canada) for his suggestions concerning FvCB model fitting.

\section{SUPPLEMENTARY MATERIAL}

The Supplementary Material for this article can be found online at: https://www.frontiersin.org/articles/10.3389/fpls.2019.01276/ full\#supplementary-material regional climatic gradient indicates limited potential to cope with temperature warming. Ann. Bot. 121, 443-457. doi: 10.1093/aob/mcx174

Bunce, J. (2018). Three methods of estimating mesophyll conductance agree regarding its $\mathrm{CO}_{2}$ sensitivity in the rubisco-limited $\mathrm{C}_{\mathrm{i}}$ range. Plants 7, 62. doi: $10.3390 /$ plants 7030062

Dash, J. P., Watt, M. S., Pearse, G. D., Heaphy, M., and Dungey, H. S. (2017). Assessing very high resolution UAV imagery for monitoring forest health 
during a simulated disease outbreak. ISPRS J. Photogram. Remote Sens. 131, 1-14. doi: 10.1016/j.isprsjprs.2017.07.007

Duursma, R. (2015). Plantecophys-an R package for analyzing and modelling leaf gas exchange data. PLoS One. doi: 10.1371/journal.pone.0143346

Furbank, R. T., and Tester, M. (2011). Phenomics-technologies to relieve the phenotyping bottleneck. Trends Plant Sci. 16, 635-644. doi: 10.1016/j. tplants.2011.09.005

Long, S. P., and Bernacchi, C. J. (2003). Gas exchange measurements, what can they tell us about the underlying limitations to photosynthesis? Procedures and sources of error. J. Exp. Bot. 54, 2393-2401. doi: 10.1093/jxb/erg262

Pilon, C., Snider, J. L., Sobolev, V., Chastain, D. R., Sorensen, R. B., Meeks, C. D., et al. (2018). Assessing stomatal and non-stomatal limitations to carbon assimilation under progressive drought in peanut (Arachis hypogaea L.). J. Plant Physiol. 231, 124-134. doi: 10.1016/j.jplph.2018.09.007

Pinheiro, J., Bates, D., DebRoy, S., Sarkar, D., and R Development Core Team. (2018). nlme: Linear and nonlinear mixed effects models. R package version 3.1-131. https://CRAN.R-project.org/package=nlme.

Rogers, A. (2014). The use and misuse of $\mathrm{V}_{c, \max }$ in Earth Systems Models. Photosynth. Res. 119, 15-29. doi: 10.1007/s11120-013-9818-1

Sendall, K. M., Reich, P. B., Zhao, C., Jihua, H., Wei, X., Stefanski, A., et al. (2015). Acclimation of photosynthetic temperature optima of temperate and boreal tree species in response to experimental forest warming. Global Change Biol. 21, 1342-1357. doi: 10.1111/gcb.12781
Stinziano, J. R., McDermitt, D. K., Lynch, D. J., Saathoff, A. J., Morgan, P. B., and Hanson, D. T. (2018). The rapid A/ $\mathrm{C}_{\mathrm{i}}$ response: a guide to best practices. New Phytol. 221: 625-627. doi: 10.1111/nph.15383

Stinziano, J. R., Morgan, P. B., Lynch, D. J., Saathoff, A. J., McDermitt, D. K., and Hanson, D. T. (2017). The rapid $A-C_{i}$ response: photosynthesis in the phenomic era. Plant Cell Environ. 40, 1256-1262. doi: 10.1111/pce.12911

Taylor, S. H., and Long, S. P. (2018). Phenotyping photosynthesis on the limit-a critical examination of RACiR. New Phytol. 221, 621-624. doi: 10.1111/nph.15382

Thompson, A. L., Thorp, K. R., Conley, M., Andrade-Sanchez, P., Heun, J. T., Dyer, J. M., et al. (2018). Deploying a proximal sensing cart to identify droughtadaptive traits in upland cotton for high-throughput phenotyping. Front. Plant Sci. 9, 507. doi: $10.3389 /$ fpls.2018.00507

Conflict of Interest: The authors declare that the research was conducted in the absence of any commercial or financial relationships that could be construed as a potential conflict of interest.

Copyright $\odot 2019$ Her Majesty the Queen in Right of Canada. This is an open-access article distributed under the terms of the Creative Commons Attribution License (CC BY). The use, distribution or reproduction in other forums is permitted, provided the original author(s) and the copyright owner(s) are credited and that the original publication in this journal is cited, in accordance with accepted academic practice. No use, distribution or reproduction is permitted which does not comply with these terms. 